\title{
EXPERIMENTAL STUDIES ON CONFINED STEEL CONCRETE COMPOSITE BEAMS UNDER PURE BENDING
}

\author{
M.Arvind ${ }^{1}$, Bollineni Nithin Krishna ${ }^{2}$, B.Sathish Kumar ${ }^{3}$, K.Shanmuga Priya ${ }^{4}$ \\ ${ }^{1}$ Dept. of Civil Engineering, $S$ A Engineering College, Chennai, India \\ ${ }^{2}$ Dept. of Civil Engineering, $S$ A Engineering College, Chennai, India \\ ${ }^{3}$ Dept. of Civil Engineering, $S$ A Engineering College, Chennai, India \\ ${ }^{4}$ Dept. of Civil Engineering, Madha Engineering College, Chennai, India
}

\begin{abstract}
An experimental investigation of the ultimate strength and behaviour of a new type of composite beam called CSCC beam (Confined Steel Concrete Composite Beam) is a concrete beam shuttered with cold formed steel sheet which acts as a composite beam by means of shear connectors and bracings. Stud shear connectors are used to take up the bond between sheet and concrete. The passive confinement by the cold formed sheet in the sides and bottom influences the strength and ductility of the system. These beams are provides very good confinement of concrete. Totally eight CSCC beams are tested and the entire behaviour of the beams are monitored to predict the physical response of the beams under three different types loading such as pure bending, pure torsion and combined bending and torsion. Two point loading was obtained for pure bending. The deformation criteria (deflection, moment and flexural rigidity) are also included in the investigation throughout the entire load history experimentally. The results obtained by the experimental values which are found to be in good agreement.
\end{abstract}

Keywords—composite beams; pure bending

\section{INTRODUCTION}

A judicious combination of structural steel and concrete utilizing the strength possessed by them and suppressing their weakness resulted in the composite construction. In present, it demands in construction on parameters such as strength, safety, serviceability, satisfactory and reliable performance expected of a structure apart from economical solutions has also made it imperative to use steel concrete composite construction techniques.

\subsection{Steel Concrete Composite Construction}

A structural member composed of two or more dissimilar materials joined together to act as a unit is referred as composite structure. It is a powerful construction concept in which compressive strength of concrete and the tensile strength of steel are almost effectively used. Steel and the concrete have almost the same thermal expansion apart from an ideal combination of strength. Hence, these essential different materials are completely compatible and complementary to each other.

\subsection{Confined Steel Concrete Composite Beam}

\section{(CSCC Beam)}

The greatest impetus for the composite construction was the development of the welded headed stud. The cold formed steel sheet is bonded to surface of concrete by means of shear connectors. Stud shear connectors are used to take up the bond between sheet and concrete. In fig.1, the passive confinement by the cold formed sheet in the sides and bottom influences the strength and ductility of the system.

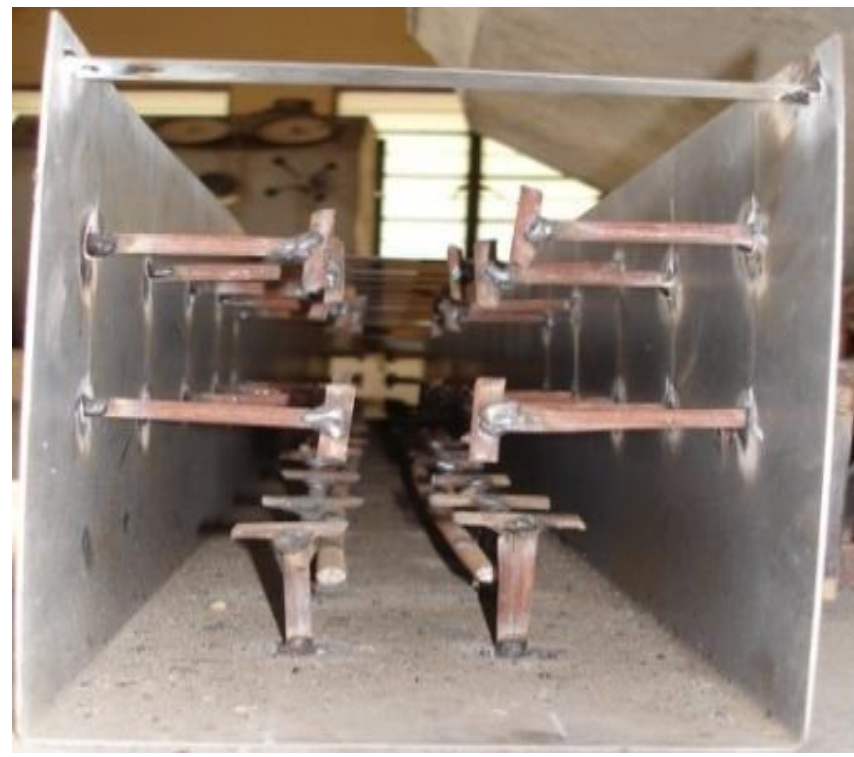

Fig. 1 CSCC Beam

\subsection{Shear Connectors and Cold Formed Steel Sheet}

Composite action between the steel and the concrete is achieved by means of mechanical connectors by the effective transfer of shear at the interface between concrete and sheet elements. These connectors are generally dubbed as "shear connectors". These connectors are responsible mainly for stability and safety of the beam against collapse. The thickness of steel sheet used in cold formed construction is usually 1 to $3 \mathrm{~mm}$. With this least thickness the sheet is used as a form work and reinforcement. 
2. EXPERIMENTAL SETUP AND TESTING PROCEDURE FOR PURE BENDING

For pure bending a total number of two composite beams with an effective span of $2.3 \mathrm{~m}$ were tested. The position of the supports, inclinometer and dial gauges points were marked on the beams. The beams were tested for two point loading. Two point loading was done inorder to apply pure bending on the beams. All the beams were designed to fail by flexure. In order to determine the curvature, the inclinometer readings were taken. For the deflections measurement, dial gauges were located at five, one at midspan, two at $1 / 6$ of the span at the bottom of the beam and two on the top of beam at supports. The test setup is shown in fig. 2. The beams were tested at a rate of loading of $30 \mathrm{kN} / \mathrm{min}$. The test was carried out until the formation of waves due to buckling of sheets of the beams. The beams began to yield and the behaviour of the beams was keenly observed from the beginning till collapse. A careful observation was made from the initial separation of sheet, propagations of cracks and failure of bracings connecting the sheet and concrete. The beams were tested to find the ultimate load carrying capacity by removing all the dial gauges and the inclinometer setup till failure.

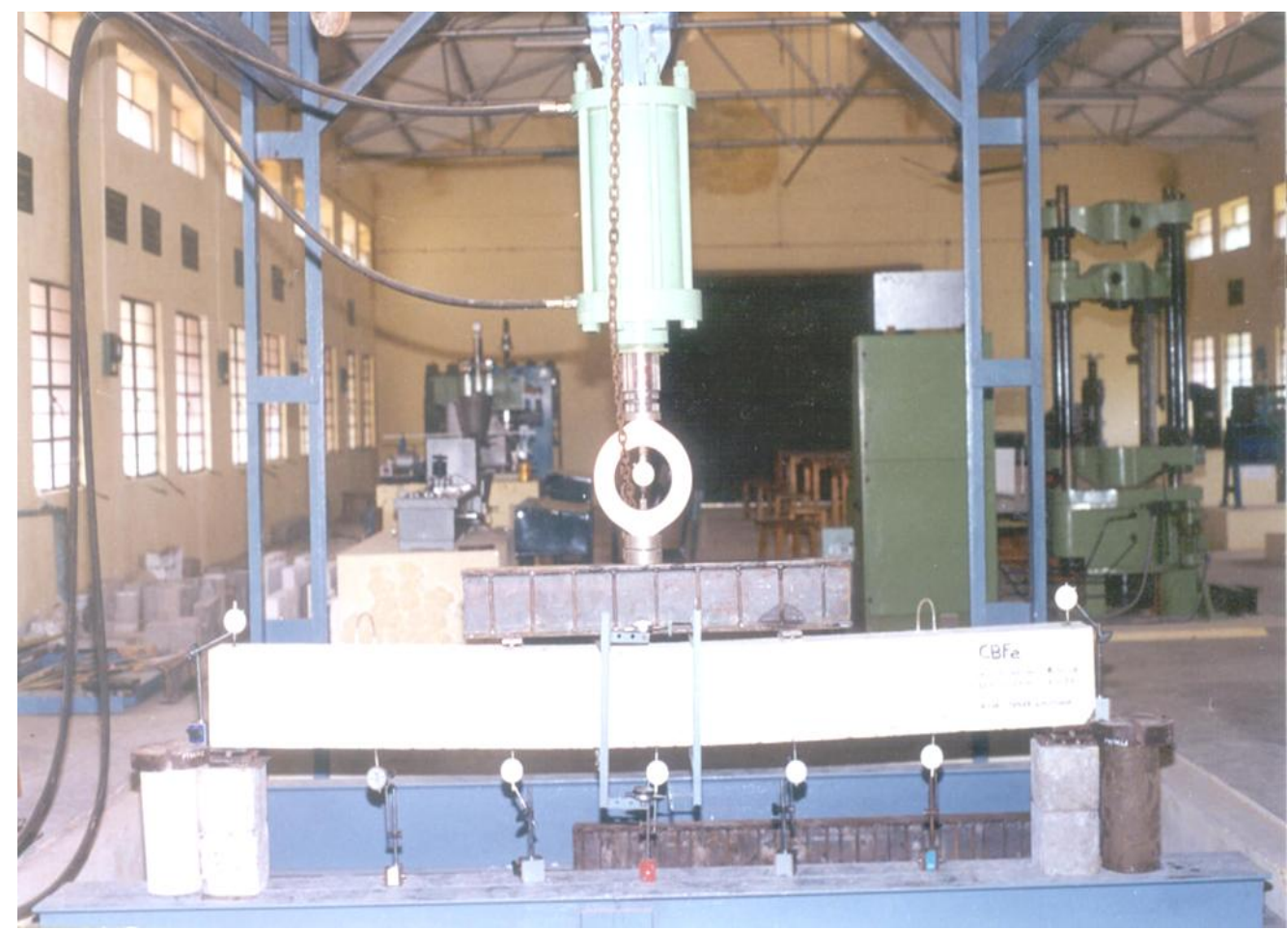

Fig. 2. Test setup for Pure Bending.

Table 1 Test Results for Pure Bending

\begin{tabular}{|c|c|c|c|c|c|}
\hline $\begin{array}{l}\text { Beam } \\
\text { ID }\end{array}$ & $\begin{array}{l}\text { Dimensi } \\
\text { ons } \\
(\mathrm{mm})\end{array}$ & $\begin{array}{l}\text { Thickness of the } \\
\text { Sheet } \\
(\mathrm{mm}) / \text { spacing of } \\
\text { bracing }(\mathrm{mm})\end{array}$ & $\begin{array}{l}\text { Ultimate } \\
\text { Load } \\
(\mathrm{kN})\end{array}$ & $\begin{array}{l}\text { Average } \\
\text { Ultimate } \\
\text { Load } \\
(\mathrm{kN})\end{array}$ & $\begin{array}{l}\text { Ultimate } \\
\text { Bending } \\
\text { Moment } \\
(\mathrm{kNm})\end{array}$ \\
\hline \multirow{2}{*}{$\mathrm{A}_{1} \mathrm{~T}_{1}$} & \multirow{2}{*}{$\begin{array}{ll}150 & x \\
230 & x \\
2300 & \end{array}$} & $1.2 / 100$ & 119 & \multirow{2}{*}{132.5} & \multirow{2}{*}{46.4} \\
\hline & & $1.2 / 150$ & 146 & & \\
\hline
\end{tabular}

\subsection{Behaviour of Beams}

The failure started with the initial separation of sheet in the form of waves due to local buckling followed by yielding of the beams. The first crack was observed followed by the appearance of several cracks which propagated in the inclined manner upon further increase of load. At failure, crushing of compression concrete and failure of bracings and yielding of tension steel were observed. 


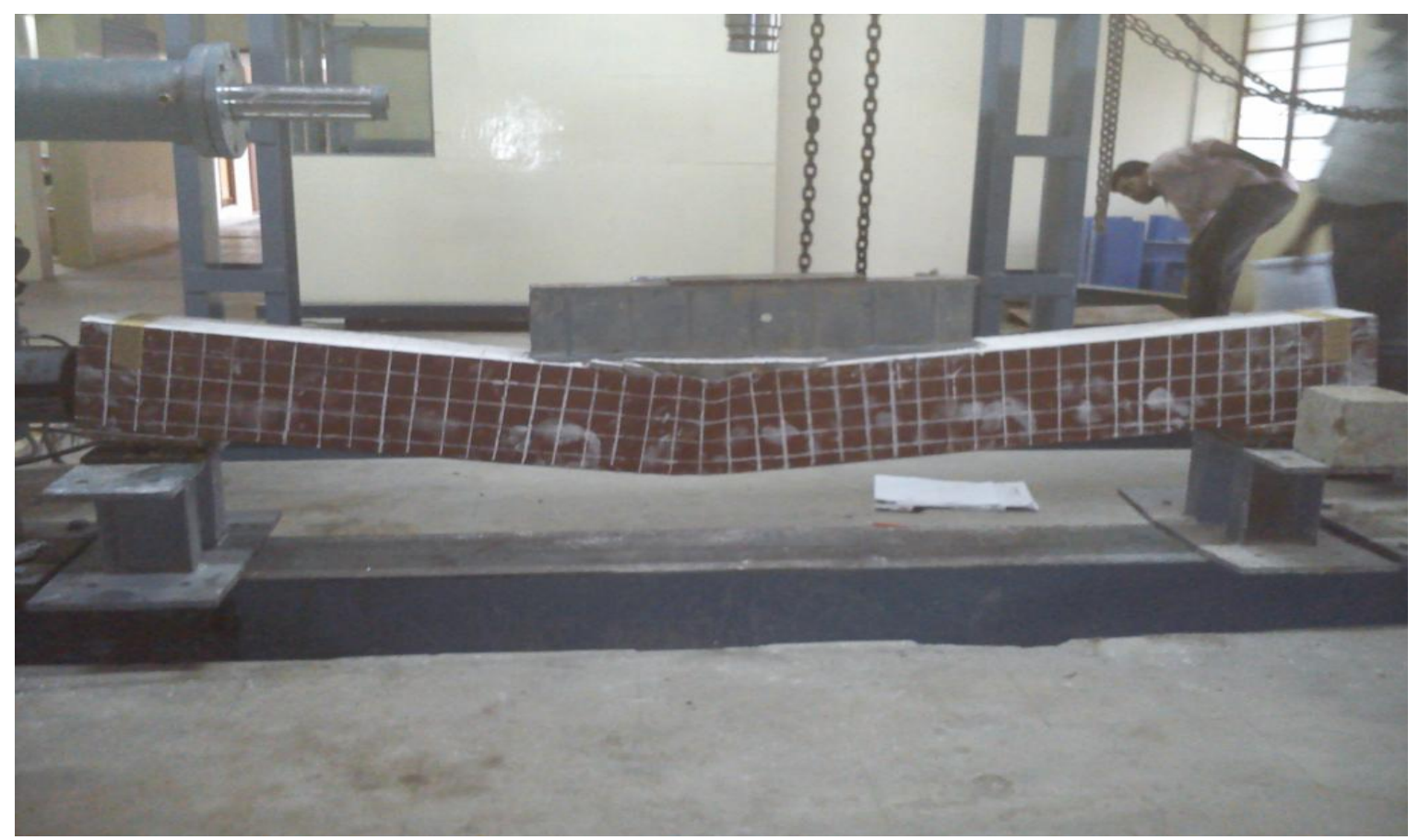

Fig.3. Failure Pattern of beam A1T1 under pure bending

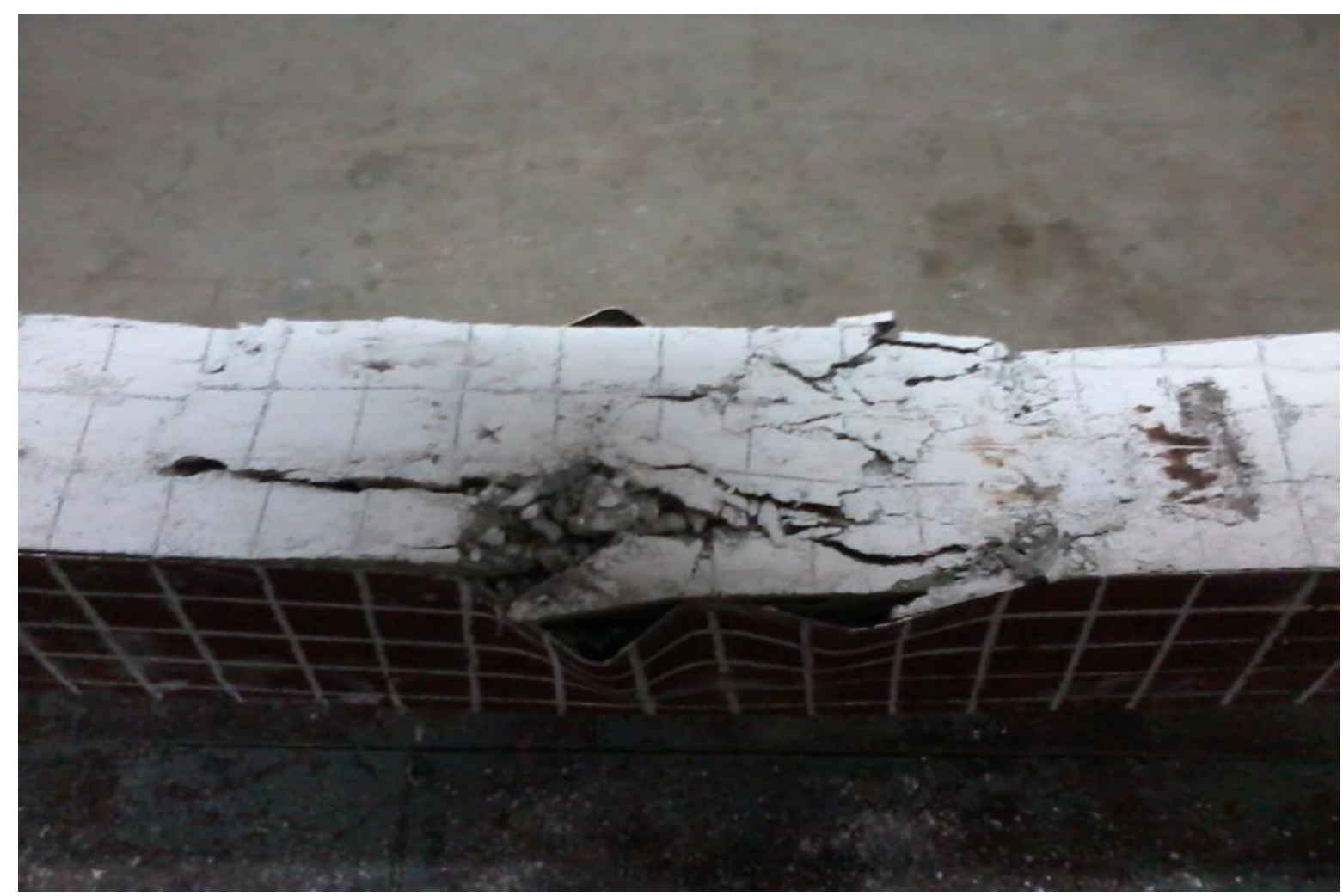

Fig. 4. Failure pattern by crushing of concrete in Pure Bending

\subsection{Variation of Load with Deflection}

Fig. 5 and Fig. 6 compares the load-deflection responses of CSCC beams under pure bending. The load deflection curves of CSCC beams are linear up to yield load and have a long plateau beyond yield load. 


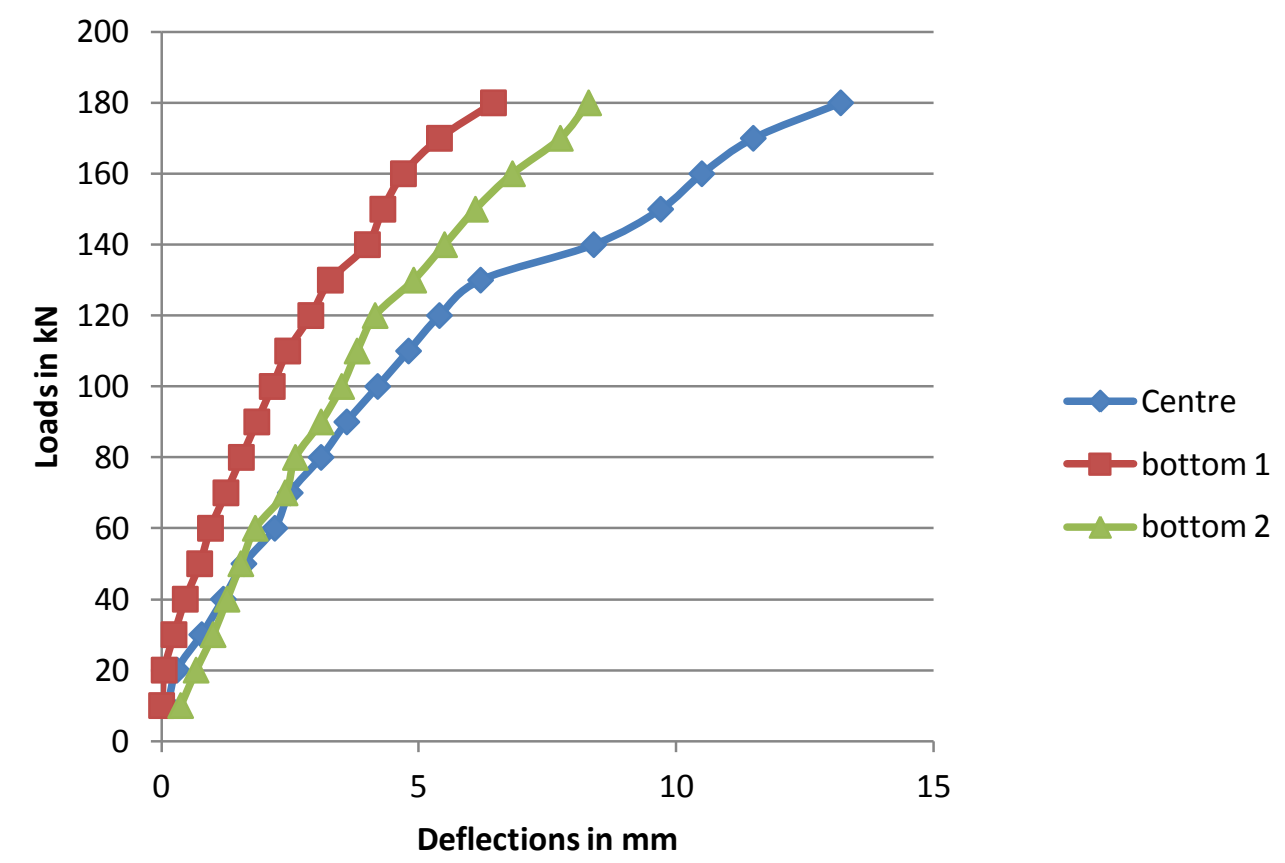

Fig. 5. Load vs. Deflection for Pure Bending (100mm spacing).

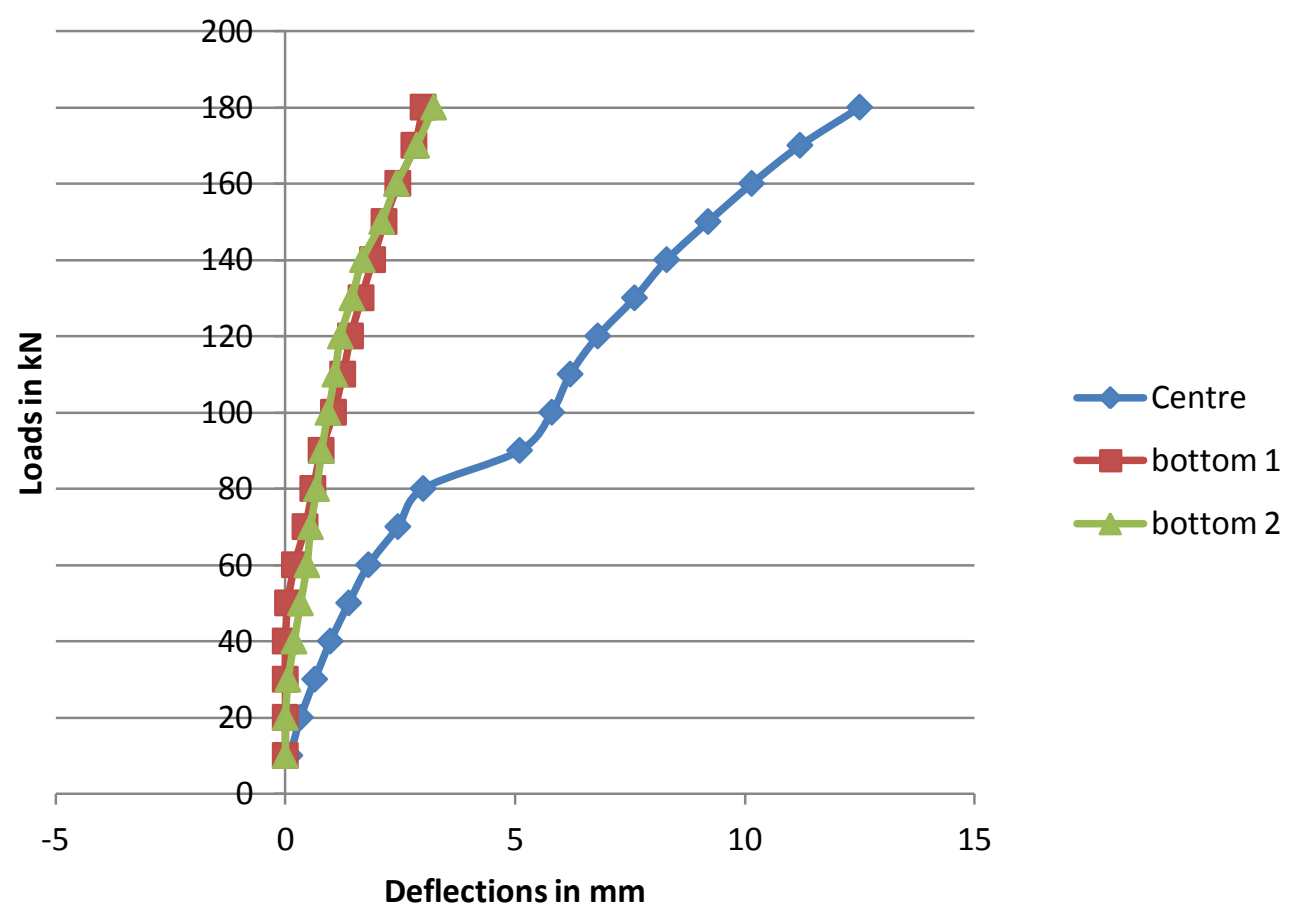

Fig. 6. Load vs. Deflection for Pure Bending (150mm spacing)

It was also found from the above graph that beams with $100 \mathrm{~mm}$ and $150 \mathrm{~mm}$ spacing of bracings have shown higher values of toughness which is an indication of the energy absorption capability of the beams. The variation in dimension of the beams has no significant influence on the above behaviour. 


\subsection{Moment Vs. Flexural Rigidity}

The flexural rigidity was computed as the ratio of applied bending moment to the curvature in the constant bending moment zone.

Flexural rigidity (EI) value was calculated as shown below:

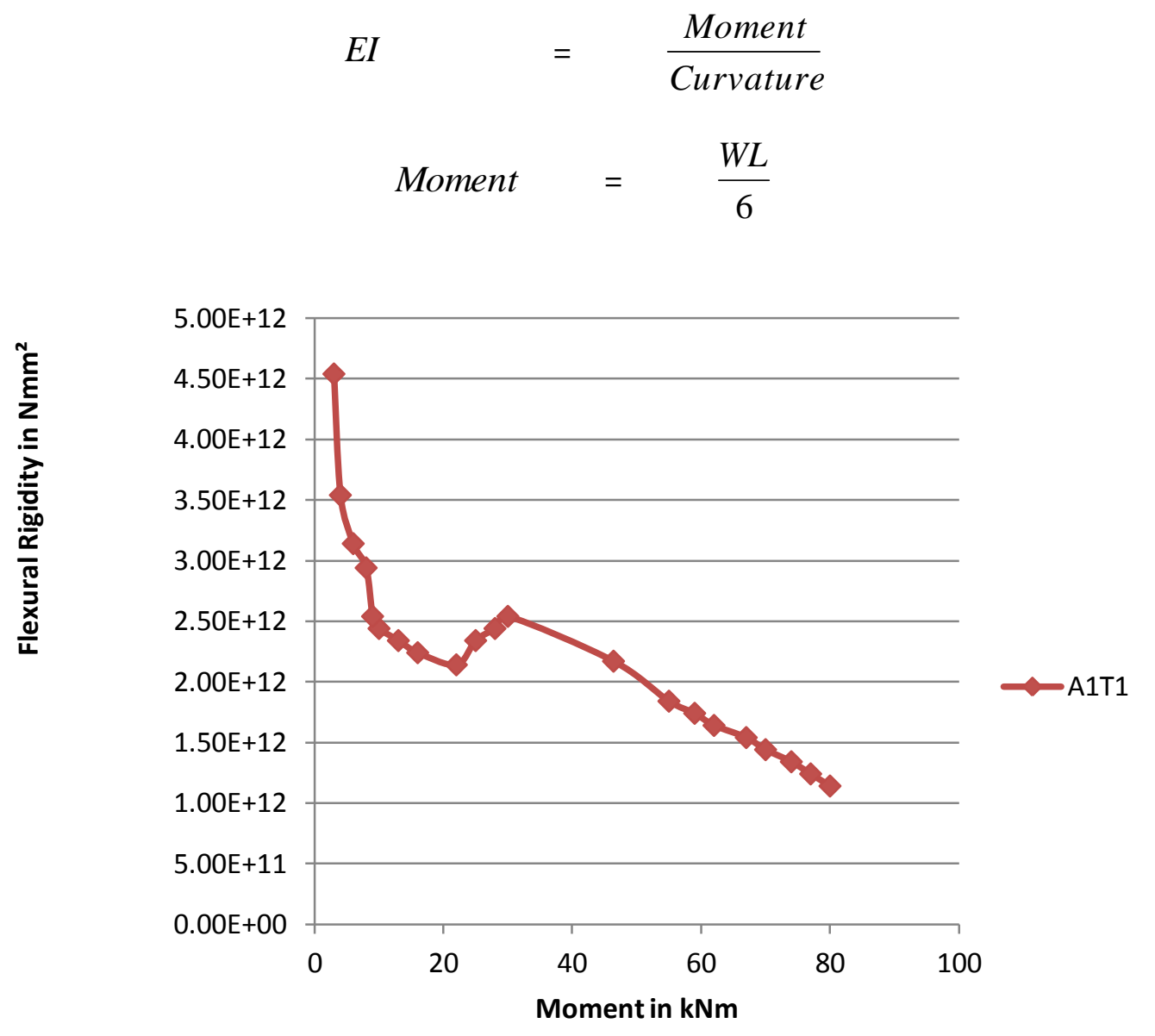

Fig. 7. Moment vs. Flexural Rigidity for Pure Bending

Fig. 7 shows the moment vs. flexural rigidity relationships for the CSCC beams under pure bending. The value of flexural rigidity decreases with the increase in moment. For beams with $100 \mathrm{~mm}$ spacing of bracings the moment carrying capacity was found to be higher than the beams with $150 \mathrm{~mm}$ spacing. The reason for the enhancement in flexural stiffness is due to closely spaced bracings which contributed additional confinement.

\section{CONCLUSION}

- The research can be extended to include the effect of shear and the shear strength capacity of the connectors.

- The effect of shear connectors to be placed at salient locations of the beam must be studied.

- The equations subjected to constant bending moment and applying twisting moment till failure can be developed.

- The research for profiled sheet as confinement can be developed.
- The beams can be tested for negative bending.

- The crossection other than the rectangular cross sections can be tried for combined loading in composite beams.

- The practical significance of the investigation is the development of Design Charts using the equations and it can be used by the design engineers directly for calculating the ultimate strength of CSCC beams under combined bending and torsion.

\section{REFERENCES}

[1] Ansourian.P. (1981), "Experiments on Continuous Composite Beams,” Proc. Inst. Civ.Engg. Part 2, 71, 25-51.

[2] Brian Uy and Mark Bradford (1995), "Ductility of Profiled Composite Beams Part.1 Experimental Study," Journal of Structural Engg, Vol.121, No.5, May 1995, pp. 876-882. 
[3] Balakrishnan S., Chapman J.C. (1964), "Experiments on Composite Beams," Struct. Eng., 42(11), 369-383.

[4] Yam.L.C.P., Chapman J.C. (1968), "The inelastic behaviour of simply supported composite beams of steel and concrete" Proc.Inst.Civ.41 (1), 651-683.

[5] Dennis Lam and Ehab Lobody (2005), "Strength analysis of steel concrete composite beams in combined bending and shear" 2005, Vol.131, No.10, pp.1593-1600.

[6] George Abdul Sayed (1982), "Composite Cold Formed Steel Concrete Beams," Journal of Structural Division, Vol.108, No.11, pp. 2609-2622.

[7] Cai C.S., Jianguo Nie (2009), "Performance of Steel-Concrete Composite Beams under Combined Bending and Torsion," Structural Engineering, Vol. 135, No. 9, September 2009, pp. 1048-1057.

[8] Johnson, R.P. (1975), "Composite Structures of Steel and Concrete," Volume-I-Blackwell Scientific Publication, London.

[9] Ray M.B. and Mallik, S.K. (1980), "Interaction of Flexure and Torsion in Steel Concrete Composite Beams," The Indian Concrete Journal.

[10] Richard, P. Nguyen (1991), "Thin Walled Cold Formed Steel Composite Beams," Journal of Structure Engg, Vol.117, October 1991, pp. 29362952. 